\title{
Dampak Gaya Pengasuhan Budaya Barat dan Timur Terhadap Perkembangan Anak
}

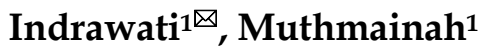 \\ Pendidikan Anak Usia Dini, Universitas Negeri Yogyakarta, Indonesia(1) \\ DOI: $\underline{10.31004 / o b s e s i . v 6 i 4.2230}$
}

\begin{abstract}
Abstrak
Gaya pengasuhan yang diterapkan orang tua berdampak pada perkembangan anak. Penelitian bertujuan memberikan gambaran bagaimana dampak gaya pengasuhan budaya barat dan timur terhadap perkembangan anak. Metode menggunakan studi literatur, dengan langkahlangkah pengumpulan sumber data, reduksi data, dan penarikan kesimpulan. Hasil penelitian ini adalah bahwa gaya pengasuhan budaya barat menganut gaya pengasuhan Baumrind, Maccoby \& Martin. Pengasuhan Baumrind meliputi pengasuhan otoriter, otoritatif, dan permisif/memanjakan; sedangkan gaya pengasuhan Maccoby \& Martin yaitu pengasuhan mengabaikan atau tidak terlibat. Pengasuhan budaya timur menganut gaya pengasuhan Baumrind, Maccoby \& Martin, dan gaya pengasuhan berbakti. Pengasuhan otoriter identik dengan perilaku negatif, otoritatif identik dengan perilaku positif, permisif identik dengan perilaku tidak mandiri, dan lalai/mengabaikan identik dengan perilaku yang beresiko, dan berbakti identik dengan mengikuti aturan orang tua. Kesimpulan penelitian ini adalah gaya pengasuhan autoritatif budaya barat maupun timur dapat menyejahterakan anak. Budaya timur melatih kemandirian anak sejak dini, sedangkan budaya timur, melatih anak dengan mendisiplinkan anak sejak dini.
\end{abstract}

Kata Kunci: gaya pengasuhan barat dan timur; perkembangan anak; anak usia dini.

\section{Abstract}

Parenting styles applied by parents have an impact on child development. This study aims to provide an overview of the impact of western and eastern cultural parenting styles on child development. The method uses a literature study, with the steps of collecting data sources, reducing data, and drawing conclusions. The results of this study are that the western culture's parenting style adheres to the Baumrind, Maccoby \& Martin parenting style. Baumrind's upbringing includes authoritarian, authoritative, and permissive/indulgent parenting; while Maccoby \& Martin's parenting style is ignoring or not involved pin parenting. Eastern cultural parenting adheres to the Baumrind, Maccoby \& Martin parenting style, and the dutiful parenting style. Authoritarian parenting is synonymous with negative behavior, authoritative is synonymous with positive behavior, permissive is synonymous with independent behavior, neglect/ignorance is synonymous with risky behavior, and filial piety is synonymous with following parental rules. The conclusion of this study is that the authoritative parenting style of western and eastern cultures can prosper children. Eastern culture trains children's independence from an early age, while Eastern culture trains children by disciplining children from an early age.

Keywords: western and eastern parenting styles; child development; early childhood

Copyright (c) 2022 Indrawati, Muthmainah

$\triangle$ Corresponding author: Indrawati

Email Address : indrawatikendari39@gmail.com (Yogyakarta, Indonesia)

Received 3 November 2022, Accepted 2 February 2022, Published 16 February 2022 


\section{PENDAHULUAN}

Anak usia dini sering disebut dengan masa golden age merupakan masa efektif dan urgen untuk diberikan stimulus pada berbagai potensi kecerdasan yang dimilikinya menuju SDM yang berkualitas (Gustiana et al., 2020). Pernyataan tersebut didukung dengan pernyataan dari (Farhurohman, 2017) bahwa masa usia dini disebut sebagai dengan usia golden age yang merupakan masa efektif untuk belajar yang dapat merangsang pertumbuhan, perkembangan maupun kecerdasan dasar seorang anak. Perkembangan anak memiliki karakteristik masing-masing sesuai dengan berbagai rangsangan yang diterimanya dari gaya pengasuhan yang diterapkan oleh orang tua. Menurut Thergaonkar \& Wadkar (Sahithya et al., 2019) bahwa gaya pengasuhan orang tua memiliki pengaruh besar terhadap perkembangan anak terutama pada usia dini. Pengasuhan yang baik adalah pengasuhan yang memberikan kehangatan pada anak (Bornstein et al., 2017). Pengasuhan yang baik akan menghasilkan keterikatan yang baik pula dengan anak (Jones et al., 2015).

Secara global, orang tua dalam mengasuh anak-anak mereka dengan cara yang berbeda-beda sesuai pengaturan dan kultur budaya mereka (Oltedal \& Nygren, 2015). Budaya adalah kepercayaan, cara hidup, seni, dan adat istiadat yang dianut dan diterima oleh orangorang dalam masyarakat tertentu (Monasterio Astobiza, 2017). Budaya mempengaruhi praktik dalam membesarkan anak karena pola asuh yang digunakan oleh orang tua adalah sering ditentukan oleh latar belakang budaya dan pendidikan mereka sendiri (Sahithya et al., 2019). Budaya membantu membangun pola asuh dan dipertahankan serta ditransmisikan dengan memengaruhi kognisi orang tua dan membentuk praktik pengasuhan (Bornstein, 2012). Pola asuh orang tua sangat dipengaruhi dengan orientasi nilai-nilai budaya (Otto, 2016).

Gaya pengasuhan merupakan seperangkat sikap dan perilaku orang tua dalam mengelola perilaku anak-anak mereka, dan ditentukan oleh pola kontrol, daya tanggap, kehangatan, dan hukuman dalam mengasuh anak (Power, 2013). Gaya pengasuhan berfokus pada kuantitas dan kualitas respons/kehangatan orang tua, kontrol/penuntutan, dan disiplin dalam pengasuhan (Power, 2013). Gaya pengasuhan mencakup keyakinan, gaya, dan praktik (Foo, 2019). Keyakinan adalah keyakinan internal tentang apa arti sesuatu. Gaya adalah tata krama yang khas di mana hal yang dilakukan. Sedangkan praktik adalah tindakan tepat yang terlibat dalam melakukan hal-hal tersebut (Foo, 2019).

Gaya pengasuhan orang tua pada umumnya menggunakan gaya pengasuhan Baumrind (meliputi gaya pengasuhan otoriter, otoritatif, permisif) dan gaya pengasuhan Maccoby dan John Martin (yaitu gaya pengasuhan mengabaikan atau lalai). Pendekatanpendekatan tersebut mempengaruhi perkembangan anak (Foo, 2019). Menurut (Zhang et al., 2017) Gaya pengasuhan orang tua pada umumnya dikelompokan ke dalam dua aliran, yaitu pengasuhan dalam masyarakat individualistik (budaya Barat) dan pengasuhan dalam masyarakat kolektivistik (budaya Timur). Menurut Wang \& Leichtman (Sahithya et al., 2019) perbedaan utama antara budaya barat dan timur adalah konsep kemerdekaan dan konsep ketergantungan. Gaya pengasuhan individualistic diartikan dengan segalanya adalah dirinya sendiri. Gaya pengasuhan budaya barat adalah dengan memberi anak kemampuan dan keterampilan individualistis untuk melanjutkan kehidupan masa depannya dan dilakukan oleh orang tua secara ketat, longgar, wajar, atau memanjakan (Foo, 2019). Orang tua Barat mendorong kemandirian, individualisme, ketegasan sosial, kepercayaan diri, dan kompetensi (Foo, 2019). Anak-anak mereka memiliki lebih banyak kebebasan untuk melakukan apa yang ingin mereka lakukan (Majumder, 2016).

Selanjutnya, gaya pengasuhan kolektivistik adalah segalanya bersama-sama dan saling ketergantungan untuk mencapai tujuan bersama (Foo, 2019). Gaya pengasuhan budaya kolektivistik timur menekankan pada keharmonisan dalam kelompok, kohesi, dan tujuan bersama (Otto, 2016). Orang tua timur terus menerus berada di sekitar anak-anak mereka sampai mencapai usia dewasa (Abubakar et al., 2015). Gaya pengasuhan orang timur sangat berwibawa namun sangat penyayang serta menjunjung tinggi kehormatan keluarga dengan perilaku dan etika yang baik (Ahmed \& Bhutto, 2016). 
Gaya pengasuhan orang tua yang mendominasi membawa pengaruh yang tidak baik terhadap perkembangan anak. Sebagaimana hasil penelitian dari (Bornstein et al., 2017) bahwa pola asuh orang tua yang lebih mengontrol pada dasarnya meningkatkan perilaku bermasalah pada perkembangan anak selanjutnya. Selain itu, hasil penelitian (Donath et al., 2014) bahwa anak-anak dari orang tua yang menolak atau mengabaikan tanpa mempertimbangkan perasaan anak, perkembangan selanjutnya menghadapi banyak risiko yang dapat membahayakan dirinya, seperti penggunaan sabu-sabu, mengonsumsi alcohol, dan banyaknya pelecehan-pelecehan yang dilakukannya terhadap orang lain.

Berdasarkan kondisi tersebut maka perlu dilakukan review pustaka terkait gaya pengasuhan orang tua terhadap perkembangan anak, mengingat stimulasi pendidikan sejak dini sangat mempengaruhi perkembangan selanjutnya. Adapun tujuan dari penulisan artikel ini adalah memberikan gambaran bagaimana gaya pengasuhan orang tua berdampak pada perkembangan anak.

\section{METODOLOGI}

Penelitian ini menggunakan metode studi literatur. Studi literatur merupakan kegiatan penelitian menggunakan data sekunder hasil dari berbagai studi kepustakaan atau literatur yang relevan dengan permasalahan penelitian yang bersumber dari buku maupun artikel atau jurnal-jurnal yang relevan. Pencarian literatur menggunakan Science Direct, Google Scholar, Mendeley, ProQuest, dan Z-Library dengan studi literatur periode 2012-2021 bersumber dari jurnal internasional, berjumlah 41 artikel untuk di review dalam penulisan literatur ini yang dirasa cocok dengan topik yang peneliti bahas.

Teknik pengumpulan data dengan mengumpulkan sejumlah artikel/jurnal internasional yang berkaitan dengan masalah dan tujuan penelitian. Teknik analisis data meliputi pengumpulan sumber data, reduksi data, dan penarikan kesimpulan. Adapun langkah-langkah untuk menganalisis penulisan artikel ini disajikan dengan bagan pada gambar 1.

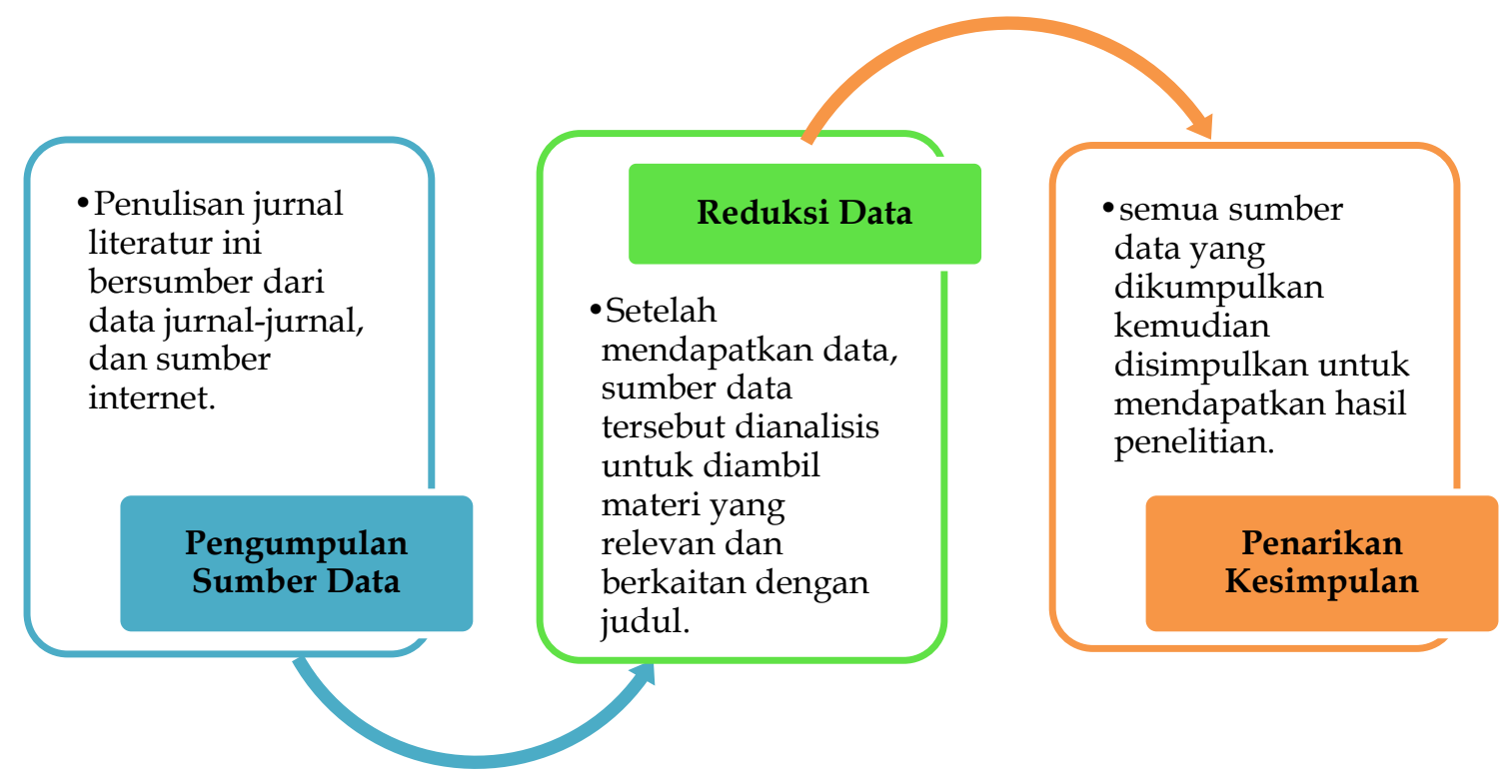

Gambar 1. Langkah-langkah Penelitian

\section{HASIL DAN PEMBAHASAN}

Menurut Foo (2019) gaya pengasuhan berdasarkan budaya diklasifkasikan menjadi dua wilayah, yaitu wilayah barat (individualistik), dan wilayah timur (kolektivistik). Lebih jelasnya dapat dilihat pada tabel 1 (lampiran) hasil review artikel relevan dengan penelitian ini. 


\section{Pembahasan}

\section{Gaya Pengasuhan Budaya Barat}

Gaya pengasuhan budaya barat yaitu memberi anak kemampuan dan keterampilan individualistis untuk melanjutkan kehidupan masa depannya. Pengasuhan orang tua dapat dilakukan secara ketat, longgar, wajar, atau memanjakan. Pendekatan-pendekatan pengasuhan orang tua barat ditinjau dari berbagai penelitian dan studi, menganut gaya pengasuhan Baumrind dan Maccoby dan Martin. Gaya pengasuhan Baumrind terdiri dari pengasuhan otoriter, otoritatif, dan permisif atau memanjakan; sedangkan gaya pengasuhan Maccoby dan Martin yaitu pengasuhan mengabaikan atau tidak terlibat. Berikut diuraikan dampak pengasuhan budaya barat pada perkembangan anak berdasarkan tinjauan pada table 1 .

Hukuman fisik yang dilakukan oleh orang tua otoriter ditemukan secara konsisten pada anak-anak dengan perilaku negatif pada perkembangan selanjutnya. Kontrol orang tua yang tinggi dikaitkan dengan masalah perilaku internal dan eksternal (Mannarini et al., 2018); seperti kecemasan (Albinhac et al., 2019); depresi, fobia sosial yang tinggi (Mousavi et al., 2016), gangguan perilaku (Eun et al., 2018), agresi, intimidasi (Gómez-Ortiz et al., 2016; Zurcher et al., 2018); tingkat penggunaan obat-obatan terlarang (Calafat et al., 2014); sikap maladaptive, seperti kekhawatiran tentang kesalahan, dan meragukan kemampuan seseorang (Hibbard \& Walton, 2014). Kontrol orang tua yang berlebihan mempengaruhi perkembangan kemandirian anak, dan mempengaruhi rasa percaya diri dan kompetensi anak, terutama dalam situasi social (Sahithya et al., 2019).

Pengasuhan orang tua dengan kehangatan yang baik atau otoritatif dikaitkan dengan hasil perkembangan positif pada anak-anak (Roskam et al., 2014). Perawatan ayah yang tinggi dikaitkan dengan fobia sosial rendah (Eun et al., 2018). Anak-anak yang orang tuanya menunjukkan perilaku yang mendukung kemandirian ditemukan memiliki orientasi motivasi yang lebih intrinsik dan menunjukkan penurunan intimidasi (Rajendran et al., 2016). Gaya pengasuhan otoritatif yang hangat dikaitkan dengan tingkat penggunaan narkoba yang lebih rendah (Calafat et al., 2014). Menurut Majumder (2016) anak-anak yang dibesarkan oleh orang tua yang otoritatif memiliki tahun-tahun sekolah yang bagus dan lebih banyak kesempatan untuk memperoleh kualifikasi yang lebih tinggi.

Gaya pengasuhan permisif atau memanjakan ditandai dengan lebih sedikit perasaan kritik dari orang tua (Hibbard \& Walton, 2014). Gaya pengasuhan yang lalai atau mengabaikan atau tidak terlibat dikaitkan dengan penggunaan alkohol lebih tinggi pada anak (Calafat et al., 2014). Menurut Donath et al. (2014) bahwa gaya pengasuhan yang menolak atau mengabaikan sangat berisiko pada perkembangan anak selanjutnya, seperti bunuh diri, merokok, dan pesta minuman keras. Menurut Majumder (2016) anak-anak yang dibesarkan oleh orang tua yang tidak terlibat lebih cenderung putus sekolah.

\section{Gaya Pengasuhan Budaya Timur}

Gaya pengasuhan budaya timur yaitu mengajarkan anak berbakti seperti mentaati dan menghormati orang tua dan nasab, mendengarkan orang dewasa, mengikuti aturan. Tanggung jawab orang tua adalah melatih dan mendisiplinkan anak (Foo, 2019). Pengasuhan orang tua timur misalnya dengan memelihara lingkungan yang aman bagi anak-anaknya, memberikan arahan pada anaknya, dan melibatkan diri dalam perkembangan anak (Huang et al., 2017). Tujuan pengasuhan budaya timur terdiri atas dua yaitu yang pertama untuk menjamin keberhasilan anak di masa depan, dan yang kedua untuk mengembangkan bakti timbal balik ketika orang tua mencapai usia tua (Foo, 2019).

Pendeketan-pendekatan pengasuhan pada budaya timur, selain mengadopsi gaya pengasuhan budaya barat yang terdiri dari empat model pengasuhan (Foo, 2019); juga ada gaya pengasuhan kelima yang digunakan orang tua di timur yang disebut dengan gaya pengasuhan berbakti, yaitu pengabdian dan perawatan orang tua akan memasukkan tuntutan 
atau harapan untuk anak-anak mereka (Moore \& Abetz, 2019). Berikut diuraikan dampak pengasuhan budaya timur pada perkembangan anak berdasarkan tinjauan pada table 1 .

Dampak pengasuhan orang tua outoritatif dikaitkan dengan kesejahteraan anak (Sahithya et al., 2019); memberikan kontribusi positif terhadap kepuasan hidup siswa (Chen, 2014); pola asuh otoritatif ibu berhubungan dengan motivasi intrinsik (Tang et al., 2018); pengasuhan otoritatif orang tua memiliki dampak yang menguntungkan pada kesehatan mental anak di kemudian hari (Uji et al., 2014; Hegde et al., 2017). Inisiatif pertumbuhan pribadi dan harga diri seseorang dipengaruhi oleh gaya pengasuhan otoritatif (Hirata \& Kamakura, 2018). Gaya pengasuhan otoritatif orang tua berhubungan positif dengan kesejahteraan psikologis siswa (Abubakar et al., 2015). Pola asuh otoritatif dikaitkan dengan tingkat kenakalan remaja yang lebih rendah (Kauser \& Pinquart, 2016).

Dampak pengasuhan orang tua otoriter tidak terkait dengan kepuasan hidup siswa (Yeung, 2016); pola asuh yang keras meningkatkan disregulasi emosional anak (Wang, 2019); gaya asuh otoriter ibu berhubungan negatif dengan introjeksi regulasi dan regulasi eksternal (Tang et al., 2018); gaya pengasuhan otoriter orang tua dapat memperburuk kesehatan mental anak di kemudian hari, seperti gejala masalah, risiko mereka untuk diri mereka sendiri dan orang lain, fungsi hidup, dan kesejahteraan psikologis (Uji et al., 2014). Pola asuh dengan kontrol yang tinggi dikaitkan dengan agresi di kalangan anak perempuan, sementara kurangnya kontrol memprediksi agresi pada anak laki-laki (Satnam et al., 2015).

Dampak pengasuhan orang tua permisif berhubungan positif dengan regulasi eksternal (Tang et al., 2018). Perlindungan orang tua yang berlebihan dikaitkan dengan masalah perilaku, ekspresi agresi tidak langsung, stres, kecemasan, harga diri rendah, dan perasaan kesepian (Jahan \& Suri, 2016). Pola asuh yang mengabaikan dikaitkan dengan tingkat kenakalan yang lebih tinggi (Kauser \& Pinquart, 2016).

\section{SIMPULAN}

Berdasarkan hasil review artikel dapat disimpulkan bahwa pengasuhan autoritatif merupakan gaya pengasuhan yang sangat berpengaruh terhadap perkembangan dan kesejahteraan mental anak dibandingkan dengan gaya pengasuhan otoriter, permisif, dan mengabaikan atau tidak terlibat baik di budaya barat maupun di budaya timur. Adapun saran untuk peneliti selanjutnya untuk mengkaji lebih lanjut gaya pengasuhan selain yang disebutkan oleh Diana Baumrind, Maccoby dan Martin, karena menurut (Foo, 2019) dalam bukunya yang berjudul Intercultural parenting: How eastern and western parenting styles affect child development terdapat gaya pengasuhan terbaru yang disebut dengan gaya pengasuhan helicopter dan gaya pengasuhan harimau.

\section{UCAPAN TERIMA KASIH}

Penulis mengucapkan terimakasih kepada dewan editor dan redaksi Jurnal Obsesi yang telah berkenan untuk menerbitkan artikel ini. Penulis juga mengucapkan terimakasih kepada Dr. Muthmainah, S.Pd., M.Pd, selaku pembimbing dalam penulisan artikel ini.

\section{DAFTAR PUSTAKA}

Abubakar, A., Van de Vijver, F. J. R., Suryani, A. O., Handayani, P., \& Pandia, W. S. (2015). Perceptions of parenting styles and their associations with mental health and life satisfaction among urban indonesian adolescents. Journal of Child and Family Studies, 24(9), 2680-2692. https:// doi.org/10.1007/s10826-014-0070-x

Ahmed, N., \& Bhutto, Z. H. (2016). Relationship between parenting styles and self compassion in young adults. Pakistan Journal of Psychological Research, 31(2), 441-451.

Akhtar, P., Malik, J. A., \& Begeer, S. (2017). The grandparents' influence: Parenting styles and social competence among children of joint families. Journal of Child and Family Studies, 26(2), 603-611. https:// doi.org/10.1007/s10826-016-0576-5 
Albinhac, A. M. H., Jean, F. A. M., \& Bouvard, M. P. (2019). Study of parental bonding in childhood in children and adolescents with anorexia nervosa. Encephale, 45(2), 121126. https:// doi.org/10.1016/j.encep.2018.02.004

Bornstein, M. H. (2012). Cultural approaches to parenting. Parenting, 12(2-3), 212-221. https://doi.org/10.1080/15295192.2012.683359

Bornstein, M. H., Putnick, D. L., Lansford, J. E., Al-Hassan, S. M., Bacchini, D., Bombi, A. S., Chang, L., Deater-Deckard, K., Di Giunta, L., Dodge, K. A., Malone, P. S., Oburu, P., Pastorelli, C., Skinner, A. T., Sorbring, E., Steinberg, L., Tapanya, S., Tirado, L. M. U., Zelli, A., \& Alampay, L. P. (2017). 'Mixed blessings': Parental religiousness, parenting, and child adjustment in global perspective. Journal of Child Psychology and Psychiatry and Allied Disciplines, 58(8), 880-892. https://doi.org/10.1111/jcpp.12705

Calafat, A., García, F., Juan, M., Becoña, E., \& Fernández-Hermida, J. R. (2014). Which parenting style is more protective against adolescent substance use? Evidence within the european context. Drug and Alcohol Dependence, 138(1), 185-192. https:// doi.org/10.1016/j.drugalcdep.2014.02.705

Chen, W. W. (2014). The relationship between perceived parenting style, filial piety, and life satisfaction in Hong Kong. Journal of Family Psychology, 28(3), 308-314. https://doi.org/10.1037/a0036819

Donath, C., Graessel, E., Baier, D., Bleich, S., \& Hillemacher, T. (2014). Is parenting style a predictor of suicide attempts in a representative sample of adolescents? BMC Pediatrics, 14(1), 1-13. https:// doi.org/10.1186/1471-2431-14-113

Eun, J. D., Paksarian, D., He, J. P., \& Merikangas, K. R. (2018). Parenting style and mental disorders in a nationally representative sample of US adolescents. Social Psychiatry and Psychiatric Epidemiology, 53(1), 11-20. https://doi.org/10.1007/s00127-017-1435$\underline{4}$

Farhurohman, O. (2017). Hakikat bermain dan permainan anak usia dini di pendidikan anak usia dini (PAUD). Jurnal Fakultas Ilmu Pendidikan, Universitas Negeri Yogyakarta, 2(1), 27-36.

Foo, K. H. (2019). Intercultural parenting: How eastern and western parenting styles affect child development. In Intercultural Parenting.

Fu, A. S., \& Markus, H. R. (2014). My mother and me: Why tiger mothers motivate asian americans but not european americans. Personality and Social Psychology Bulletin, 40(6), 739-749. https:// doi.org/10.1177/0146167214524992

Gómez-Ortiz, O., Romera, E. M., \& Ortega-Ruiz, R. (2016). Parenting styles and bullying. The mediating role of parental psychological aggression and physical punishment. Child Abuse and Neglect, 51, 132-143. https:// doi.org/10.1016/j.chiabu.2015.10.025

Gustiana, E., Mayasarokh, M., \& Dewi, A. R. T. (2020). Perilaku sosial emosional anak usia dini. Jurnal Golden Age, 4(01), 181-190. https:// doi.org/10.29408/iga.v4i01.2233

Hegde, A., Kamath, A., \& Roy, K. (2017). Is parenting a determinant of adolescent mental health? - A population based study in South India. International Journal of Adolescent Medicine and Health, 29(3). https:// doi.org/10.1515/ijamh-2015-0090

Hibbard, D. R., \& Walton, G. E. (2014). Exploring the development of perfectionism: The influence of parenting style and gender. Social Behavior and Personality, 42(2), 269278. https://doi.org/10.2224/sbp.2014.42.2.269

Hirata, H., \& Kamakura, T. (2018). The effects of parenting styles on each personal growth initiative and self-esteem among Japanese university students. International Journal of Adolescence and Youth, 23(3), 325-333. https:// doi.org/10.1080/02673843.2017.1371614

Hou, X., Gong, Z., Yan, Z., Su, Y., \& Zuo, X. (2019). Children's theory of mind development: Cultural perspectives. Kexue Tongbao/Chinese Science Bulletin, 64(4), 384-392. https:// doi.org/10.1360/N972018-00763 
Huang, C. Y., Cheah, C. S. L., Lamb, M. E., \& Zhou, N. (2017). Associations between parenting styles and perceived child effortful control within chinese families in the united states, the united kingdom, and taiwan. Journal of Cross-Cultural Psychology, 48(6), 795-812. https://doi.org/10.1177/0022022117706108

Jahan, A., \& Suri, S. (2016). Parenting style in relation to mental health among female adolescents. Abnormal and Behavioural Psychology, 02(03), 3-6. https://doi.org/10.4172/2472-0496.1000125

Jones, J. D., Cassidy, J., \& Shaver, P. R. (2015). Parents' self-reported attachment styles: A review of links with parenting behaviors, emotions, and cognitions. Personality and Social Psychology Review, 19(1), 44-76. https://doi.org/10.1177/1088868314541858

Kauser, R., \& Pinquart, M. (2016). Gender differences in the associations between perceived parenting styles and juvenile delinquency in Pakistan. Pakistan Journal of Psychological Research, 31(2), 549-568.

Kooraneh, A. E., \& Amirsardari, L. (2015). Predicting early maladaptive schemas using Baumrind's parenting styles. Iranian Journal of Psychiatry and Behavioral Sciences, 9(2), 26-30. https://doi.org/10.5812/ijpbs.952

Kuppens, S., \& Ceulemans, E. (2019). Parenting styles: A closer look at a well-known concept. Journal of Child and Family Studies, 28(1), 168-181. https://doi.org/10.1007/s10826$\underline{018-1242-x}$

Majumder, M. A. (2016). The impact of parenting style on children's educational outcomes in the united states. Journal of Family and Economic Issues, 37(1), 89-98. https:// doi.org/10.1007/s10834-015-9444-5

Mannarini, S., Balottin, L., Palmieri, A., \& Carotenuto, F. (2018). Emotion regulation and parental bonding in families of adolescents with internalizing and externalizing $\begin{array}{llll}\text { symptoms. Frontiers in } & \text { Psychology, }\end{array}$ https://doi.org/10.3389/fpsyg.2018.01493

Monasterio Astobiza, A. (2017). What is culture in cultural economy? Defining culture to create measurable models in cultural economy. ARBOR Ciencia, Pensamiento y Cultura, 193(783), 376. https://doi.org/10.3989/arbor.2017.783n1007

Moore, J., \& Abetz, J. S. (2019). What do parents regret about having children? Communicating regrets online. Journal of Family Issues, 40(3), 390-412. https://doi.org/10.1177/0192513X18811388

Mousavi, S. E., Low, W. Y., \& Hashim, A. H. (2016). Perceived parenting styles and cultural influences in adolescent's anxiety: A cross-cultural comparison. Journal of Child and Family Studies, 25(7), 2102-2110. https://doi.org/10.1007/s10826-016-0393-x

Oltedal, S., \& Nygren, L. (2015). Local family definitions matter. Journal of Comparative Social Work, 10(1), 1-5. https:// doi.org/10.31265/jcsw.v10i1.119

Otto, W. J. (2016). What teachers should know about why these students perform so well: An examination of korean-american achievement through student perspectives of east asian parenting beliefs, styles and practices. International Electronic Journal of Elementary Education, 8(4), 167-181. http://search.ebscohost.com/login.aspx?direct=true\&db=eric\&AN=EJ1126677\&site= ehost-live

Power, T. G. (2013). Parenting dimensions and styles: A brief history and recommendations for future research. Childhood Obesity, 9(SUPPL.1), 14-21. https://doi.org/10.1089/chi.2013.0034

Rajendran, K., Kruszewski, E., \& Halperin, J. M. (2016). Parenting style influences bullying: A longitudinal study comparing children with and without behavioral problems. Journal of Child Psychology and Psychiatry and Allied Disciplines, 57(2), 188-195. https://doi.org/10.1111/jcpp.12433 
Rinaldi, C. M., \& Howe, N. (2012). Mothers' and fathers' parenting styles and associations with toddlers' externalizing, internalizing, and adaptive behaviors. Early Childhood Research Quarterly, 27(2), 266-273. https:// doi.org/10.1016/j.ecresq.2011.08.001

Roskam, I., Stievenart, M., Meunier, J. C., \& Noël, M. P. (2014). The development of children's inhibition: Does parenting matter? Journal of Experimental Child Psychology, 122(1), 166-182. https://doi.org/10.1016/j.jecp.2014.01.003

Sahithya, B. R., Manohari, S. M., \& Vijaya, R. (2019). Parenting styles and its impact on children-a cross cultural review with a focus on India. Mental Health, Religion and Culture, 22(4), 357-383. https:// doi.org/10.1080/13674676.2019.1594178

Satnam, M., Johal, K., Kiranjot Kaur, M., \& Professor, A. (2015). Adolescent aggression and parental behaviour: A correlational study. IOSR Journal Of Humanities And Social Science Ver. III, 20(7), 22-27. https:/ / doi.org/10.9790/0837-20732227

Shechory-Bitton, M., Ben David, S., \& Sommerfeld, E. (2015). Effect of ethnicity on parenting styles and attitudes toward violence among jewish and arab muslim israeli mothers: An intergenerational approach. Journal of Cross-Cultural Psychology, 46(4), 508-524. https:// doi.org/10.1177/0022022115576001

Tang, J., Li, N., Sandoval, J. R., \& Liu, Y. (2018). Parenting styles and academic motivation: A sample from chinese high schools. Journal of Child and Family Studies, 27(10), 33953401. https:// doi.org/10.1007/s10826-018-1164-7

Uji, M., Sakamoto, A., Adachi, K., \& Kitamura, T. (2014). The impact of authoritative, authoritarian, and permissive parenting styles on children's later mental health in japan: Focusing on parent and child gender. Journal of Child and Family Studies, 23(2), 293-302. https:// doi.org/10.1007/s10826-013-9740-3

Wang, M. (2019). Harsh parenting and adolescent aggression: Adolescents' effortful control as the mediator and parental warmth as the moderator. Child Abuse and Neglect, 94(July 2018), 104021. https:// doi.org/10.1016/j.chiabu.2019.05.014

Yeung, J. W. K. (2016). Parenting discrepancies in the aggregate parenting context and positive child outcomes in Chinese parent-child dyads. Personality and Individual Differences, 98, 107-113. https://doi.org/10.1016/j.paid.2016.03.064

Zhang, W., Wei, X., Ji, L., Chen, L., \& Deater-Deckard, K. (2017). Reconsidering parenting in chinese culture: Subtypes, stability, and change of maternal parenting style during early adolescence. Journal of Youth and Adolescence, 46(5), 1117-1136. https:// doi.org/10.1007/s10964-017-0664-x

Zurcher, J. D., Holmgren, H. G., Coyne, S. M., Barlett, C. P., \& Yang, C. (2018). Parenting and cyberbullying across adolescence. Cyberpsychology, Behavior, and Social Networking, 21(5), 294-303. https:// doi.org/10.1089/cyber.2017.0586 


\section{Lampiran}

Tabel 1. Data Relevan Dengan Penelitian Ini

\begin{tabular}{|c|c|c|}
\hline No & Autors & Title \\
\hline 1. & $\begin{array}{l}\text { (Abubakar } \\
\text { et al., 2015) }\end{array}$ & $\begin{array}{l}\text { Perceptions of parenting } \\
\text { styles and their associations } \\
\text { with mental health and life } \\
\text { satisfaction among urban } \\
\text { indonesian adolescents }\end{array}$ \\
\hline 2. & $\begin{array}{l}\text { (Ahmed \& } \\
\text { Bhutto, } \\
\text { 2016) }\end{array}$ & $\begin{array}{l}\text { Relationship between } \\
\text { parenting styles and self } \\
\text { compassion in young adults }\end{array}$ \\
\hline
\end{tabular}

Pola asuh otoritatif di Barat berefek positif pada anak tetapi tidak meniru asosiasi negatif dari pola asuh otoriter.

Analisis mengungkapkan hubungan yang tidak signifikan antara pola asuh (otoritatif, otoriter, dan permisif) dan welas asih. Namun analisis regresi berganda dari gaya pengasuhan dan subskala kasih sayang diri menunjukkan signifikan hubungan antara gaya pengasuhan permisif dan isolasi.

3. (Akhtar et The grandparents' influence: Perkembangan psikososial, kedekatan al., 2017) Parenting styles and social competence among children of joint families

4. (Albinhac et Study of parental bonding in al., 2019) childhood in children and adolescents with anorexia nervosa

emosional anak dengan kakek-nenek berfungsi sebagai pelindung terhadap kondisi keluarga yang abai.

Studi ini menunjukkan peringkat oleh orang tua yang hangat dan pengertian, ibu yang terlalu protektif dan ayah yang mendorong otonomi. Ada overprotection ibu dan ayah pada anoreksia nervosa pubertas dibandingkan dengan peripubertal.

5. (Bornstein, Cultural approaches to Studi budaya memberi tahu kita tentang 2012) parenting penyesuaian timbal balik orang tua dan anakanak dalam hal tuntutan yang diperlukan secara universal dan diinginkan secara kontekstual. Implikasi kebijakan sosial serta arah masa depan yang didorong oleh pendekatan budaya untuk mengasuh anak

6. (Bornstein 'Mixed blessings': Parental et al., 2017) religiousness, parenting, and child adjustment in global perspective

7. (Calafat et Which parenting style is more al., 2014) protective against adolescent substance use? Evidence within the european context

8. (Chen, 2014) The relationship between perceived parenting style, filial piety, and life satisfaction in Hong Kong

Orang tua dan anak-anak setuju bahwa religiusitas orang tua dikaitkan dengan pola asuh yang lebih mengontrol dan, pada gilirannya, meningkatkan perilaku bermasalah anak. Namun, anak-anak melihat religiusitas terkait dengan penolakan orang tua, sedangkan orang tua melihat religiusitas terkait dengan kemanjuran dan kehangatan orang tua, yang memiliki asosiasi berbeda dengan fungsi anak. Kedua gaya pengasuhan memanjakan dan otoritatif dikaitkan dengan hasil yang lebih baik daripada pola asuh otoriter dan lalai di semua negara yang diteliti.

Pola asuh otoritatif yang dirasakan dikaitkan dengan kesalehan berbakti timbal balik dan memberikan kontribusi positif terhadap kepuasan hidup orang dewasa muda. Baik pola asuh yang dianggap otoritatif maupun otoriter dikaitkan dengan kesalehan berbakti yang otoriter, tetapi kesalehan berbakti yang otoriter tidak dikaitkan dengan kepuasan hidup orang dewasa muda.

9. (Donath et Is parenting style a predictor Anak-anak dari orang tua yang Berwibawa al., 2014) of suicide attempts in a mendapat untung, anak-anak dari orang tua 


\begin{tabular}{|c|c|c|}
\hline No & Autors & Title \\
\hline 10. & $\begin{array}{l}\text { (Eun et al., } \\
2018 \text { ) }\end{array}$ & $\begin{array}{l}\text { representative sample of } \\
\text { adolescents? } \\
\text { Parenting style and mental } \\
\text { disorders in a nationally } \\
\text { representative sample of US } \\
\text { adolescents }\end{array}$ \\
\hline 11. & (Foo, 2019) & $\begin{array}{l}\text { Intercultural parenting: How } \\
\text { eastern and western } \\
\text { parenting styles affect child } \\
\text { development }\end{array}$ \\
\hline 12. & $\begin{array}{l}(\mathrm{Fu} \\
\text { Markus, } \\
2014)\end{array}$ & $\begin{array}{l}\text { My mother and me: Why } \\
\text { tiger mothers motivate asian } \\
\text { americans but not european } \\
\text { americans }\end{array}$ \\
\hline 13. & $\begin{array}{l}\text { (Gómez- } \\
\text { Ortiz et al., } \\
2016 \text { ) }\end{array}$ & $\begin{array}{l}\text { Parenting styles and bullying. } \\
\text { The mediating role of } \\
\text { parental psychological } \\
\text { aggression and physical } \\
\text { punishment }\end{array}$ \\
\hline
\end{tabular}

14. (Hegde et Is parenting a determinant of al., 2017) adolescent mental health? - A population based study in South India

15. (Hibbard \& Exploring the development of Walton, perfectionism: The influence 2014) of parenting style and gender

16. (Hirata \& The effects of parenting styles Kamakura, on each personal growth 2018) initiative and self-esteem among Japanese university students

17. (Hou et al., Children's theory of mind 2019) development: Cultural perspectives

Study Result
$\begin{aligned} & \text { yang Menolak-Mengabaikan berada dalam } \\ & \text { risiko. }\end{aligned}$

Perawatan dan kontrol orang tua yang dirasakan berhubungan dengan gangguan mental remaja setelah mengontrol beberapa potensi pembaur. Diferensial pola asosiasi ditemukan menurut jenis kelamin remaja dan ras/etnis.

Pengasuhan budaya barat, memandirikan anak sejak dini, sedangkan budaya timur, mendisiplinkan anak sejak dini.

Siswa AA dibandingkan dengan siswa sekolah menengah EA mengalami lebih banyak ketergantungan dengan ibu mereka dan tekanan dari mereka, tetapi tekanan itu tidak meregangkan hubungan mereka dengan ibu mereka. EA dimotivasi oleh ibu mereka, dan AA secara khusus dimotivasi oleh tekanan dari ibu mereka.

Gaya pengasuhan non-demokratis mendukung penggunaan disiplin hukuman, yang meningkatkan risiko keterlibatan intimidasi remaja.

Proporsi remaja dengan IPR yang baik dengan orang tua dilaporkan memiliki status kesehatan mental yang lebih baik dan keterlibatan yang rendah dalam aktivitas terkait kekerasan. Sekolah juga menunjukkan efek serupa. Lingkungan, teman sebaya tidak menunjukkan pengaruh yang signifikan terhadap kesehatan mental remaja. Prediktor paling signifikan untuk kesehatan mental remaja adalah IPR dengan orang tua dan di sekolah

Gaya pengasuhan otoriter dikaitkan dengan aspek perfeksionisme yang lebih maladaptif kekhawatiran tentang kesalahan, meragukan kemampuan seseorang), sedangkan pola asuh otoritatif tampaknya melindungi individu dari aspek maladaptif ini. Secara umum, pengasuhan yang memanjakan dikaitkan dengan lebih sedikit perasaan kritik dari orang tua, sedangkan pengasuhan yang lalai dikaitkan dengan lebih banyak perasaan kritik. Pentingnya pengaruh gaya asuh otoritatif terhadap masing-masing PGI dan harga diri di kalangan mahasiswa universitas Jepang

Dalam praktik pengasuhan keluarga, orang tua Barat lebih banyak berbicara tentang istilah kondisi mental, dan cenderung mengadopsi gaya pengasuhan otoritatif. Sebaliknya, orang tua Timur lebih banyak merujuk tindakan dan konsekuensinya dalam pembicaraan orang tua- 


\begin{tabular}{|c|c|c|}
\hline No & Autors & Title \\
\hline 18. & $\begin{array}{l}\text { (Huang et } \\
\text { al., 2017) }\end{array}$ & $\begin{array}{l}\text { Associations between } \\
\text { parenting styles and } \\
\text { perceived child effortful } \\
\text { control within chinese } \\
\text { families in the united states, } \\
\text { the united kingdom, and } \\
\text { Taiwan }\end{array}$ \\
\hline
\end{tabular}

19. (Jahan \& Parenting style in relation to Suri, 2016) mental health among female adolescents

20. (Jones et al., Parents' self-reported 2015) attachment styles: A review of links with parenting behaviors, emotions, and cognitions

21. (Kauser \& Gender differences in the Pinquart, associations between 2016) perceived parenting styles and juvenile delinquency in

22. (Kooraneh Predicting early maladaptive \& schemas using Baumrind's Amirsardari parenting styles , 2015)

23 (Kuppens \& Ceulemans, 2019)

(Majumder, The impact of parenting style 2016)

$25 \quad$ (Mannarini et al., 2018)

(Moore \& What do parents regret about Abetz, 2019) having Communicating online outcomes in the united states Emotion regulation and parental bonding in families of adolescents with internalizing and externalizing symptoms Pakistan

anak, dan cenderung mengadopsi gaya pengasuhan otoriter.

Perbedaan kelompok budaya yang signifikan dalam gaya pengasuhan otoriter ibu.

Masalah perilaku anak disebabkan pengasuhan gaya pemeliharaan paten. Meningkatnya tingkat stres dan kecemasan di lingkungan keluarga, yang pada gilirannya mempengaruhi hubungan orang tua-anak, disebabkan karena pola asuh yang tidak teratur.

Kelekatan orang dewasa dan pengasuhan anak akan sangat diuntungkan dari peningkatan kolaborasi di antara para peneliti dari tradisi penelitian keterikatan sosial dan perkembangan

Tipologi pola asuh Baumrind adalah

berlaku di negara berkembang seperti

Pakistan. Ada lebih banyak persamaan daripada perbedaan hasil antara negara-negara Barat dan Pakistan.

Gaya pengasuhan otoritatif memiliki beberapa fitur seperti menunjukkan tingkat kehangatan yang tinggi atau mendorong anak-anak untuk mengekspresikan pendapat mereka sendiri yang mungkin berbeda. Namun, gaya pengasuhan otoriter memiliki sifat-sifat seperti tidak berperasaan, tidak berperasaan, ketat, dan kurang memperhatikan kebutuhan perkembangan anak-anak, yang tidak dapat diterima.

Akuntansi untuk kontrol psikologis orang tua tidak menghasilkan gaya pengasuhan tambahan, tetapi meningkatkan pemahaman kita tentang pola di antara tiga dimensi pengasuhan dalam setiap gaya pengasuhan dan hubungannya dengan hasil anak

Gaya pengasuhan otoritatif ditemukan sebagai yang terbaik di antara semua jenis gaya pengasuhan Adanya transmisi antargenerasi dari ikatan orang tua tertentu, yang dapat mempengaruhi regulasi emosional dan oleh karena itu manifestasi gejala kejiwaan.
Orang tua mengartikulasikan bahwa jika mereka dapat kembali ke masa lalu, mereka tidak akan memiliki anak. Percakapan di forum online melegitimasi penyesalan emosi sebagai 


\begin{tabular}{lll}
\hline No & Autors & \multicolumn{1}{c}{ Title } \\
\hline & & \\
27 & $\begin{array}{l}\text { (Mousavi et } \\
\text { al., 2016) }\end{array}$ & $\begin{array}{l}\text { Perceived parenting styles } \\
\text { and cultural influences in } \\
\text { adolescent's anxiety: A cross- } \\
\end{array}$ \\
& & cultural comparison
\end{tabular}

Study Result

orang tua, yang bertentangan dengan norma sosial dan emosional peran ibu dan ayah

Penolakan orang tua, pengasuhan yang cemas, dan kontrol/perlindungan lebih berkorelasi dengan kecemasan yang lebih tinggi terlepas dari kelompok budaya tetapi asosiasi ini lebih kuat untuk orang bule. Gaya pengasuhan sebagai prediktor kecemasan ditemukan berbeda secara lintas budaya.

28 (Otto, 2016) What teachers should know about why these students perform so well: An examination of koreanamerican achievement through student perspectives of east asian parenting beliefs, styles and practices

29 (Power, Parenting dimensions and 2013) styles: A brief history and recommendations for future research

30 (Rajendran Parenting style influences et al., 2016) bullying: A longitudinal study comparing children with and without behavioral problems

31 (Rinaldi \& Mothers' and fathers' Howe, 2012) parenting styles and associations with toddlers' externalizing, internalizing, and adaptive behaviors

32 (Roskam et The development of al., 2014) children's inhibition: Does parenting matter?

33 (Sahithya et Parenting styles and its al., 2019) impact on children-a cross cultural review with a focus on India

34 (Satnam et Adolescent aggression and al., 2015) parental behaviour: A correlational study

35 (Shechory- Effect of ethnicity on Bitton et al., parenting styles and attitudes 2015) toward violence among jewish and arab muslim

Guru pra-jabatan, dan orang lain yang terlibat dalam pendidikan siswa Korea-Amerika tentang faktor pembeda (yaitu, praktik orang tua dan/atau pengajaran Asia Timur tertentu) yang mungkin berpengaruh untuk menjelaskan dan meningkatkan prestasi akademik bagi siswa

Gaya pengasuhan yang diidentifikasi oleh Baumrind2 dan dielaborasi oleh Maccoby dan Martin4 masih merupakan satu-satunya gaya pengasuhan dengan dasar empiris yang kuatsetidaknya dalam budaya Barat

Dukungan orang tua yang lebih besar untuk otonomi anak pada usia 4-5 tahun terkait dengan pengurangan bullying. Intervensi yang mendorong dukungan orang tua untuk otonomi anak pada saat masuk sekolah dapat mengurangi intimidasi selama tahun-tahun awal sekolah.

Pola asuh permisif oleh ibu dan pola asuh otoriter oleh ayah secara unik dan signifikan memprediksi perilaku eksternalisasi balita, sementara pola asuh otoritatif dari ayah memprediksi perilaku adaptif

Perilaku pengasuhan yang melibatkan pemantauan yang lebih tinggi, disiplin yang lebih rendah, inkonsistensi dan pengendalian negatif, dan gaya pengasuhan yang positif dikaitkan dengan perkembangan kapasitas penghambatan yang baik pada anak-anak.

Gaya pengasuhan memanjakan/permisif ditemukan di kedua negara Barat dan di India

Terdapat hubungan positif yang signifikan antara agresi pada remaja dengan perilaku orang tua yang menyimpang. Orang tua menunjukkan pola asuh yang lebih menyimpang terhadap anak perempuan dibandingkan dengan anak laki-laki dalam beberapa dimensi.

Pengasuhan wanita Muslim lebih rendah dalam gaya otoritatif dan lebih tinggi pada gaya otoriter dan permisif daripada wanita 
DOI: 10.31004/obsesi.v6i4.2230

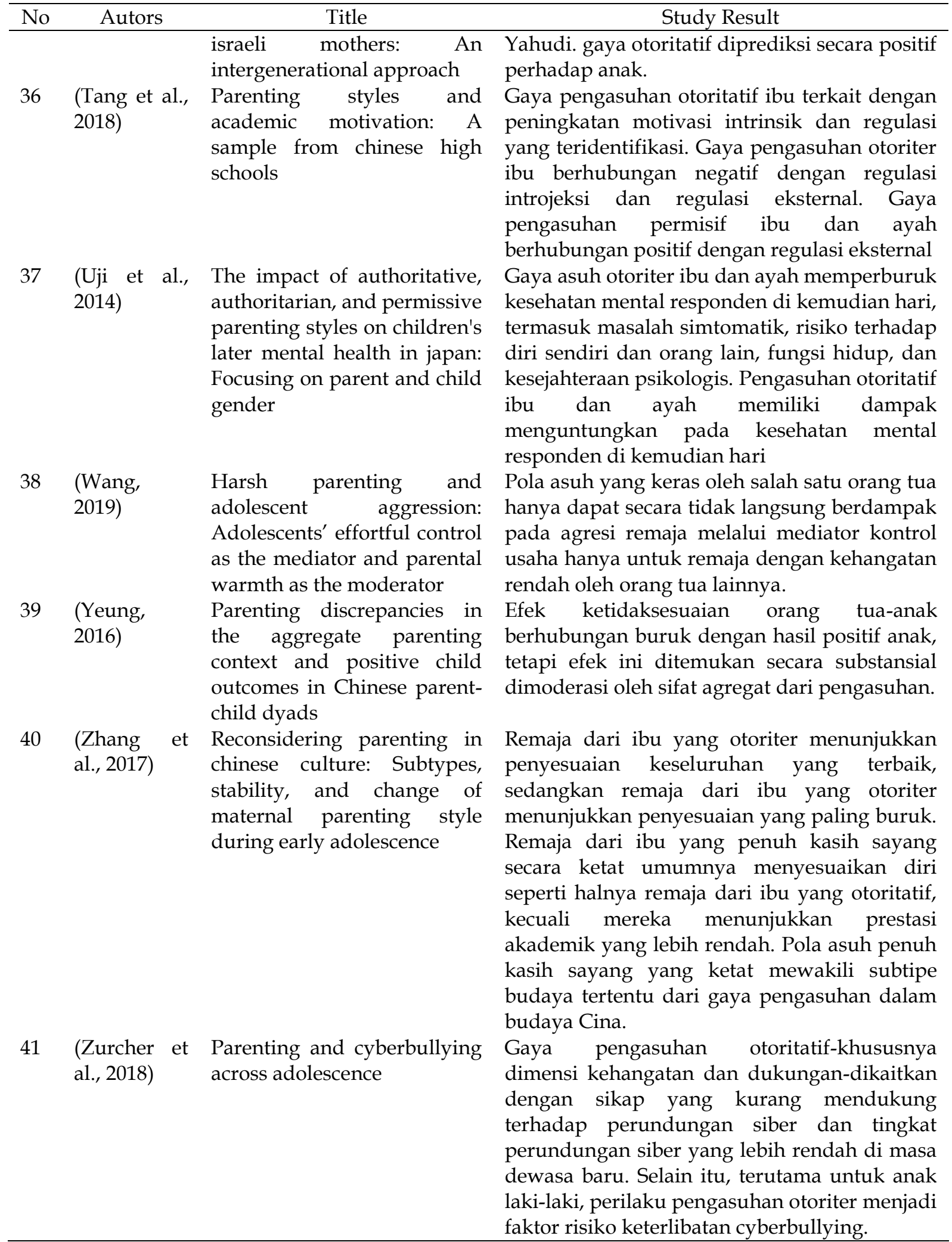

